\title{
A INFLUÊNCIA DO PENSAMENTO DE FRANTZ FANON NA PRODUÇÃO INTELECTUAL NEGRA FEMININA
}

\author{
THE INFLUENCE OF FRANTZ FANON'S THOUGHT \\ IN BLACK FEMALE INTELLECTUAL PRODUCTION
}

\section{Rosemere Ferreira da Silva ${ }^{1}$}

\begin{abstract}
Resumo: O artigo em evidência discute a entrada do pensamento de Frantz Fanon no Brasil, com destaque à importância da produção intelectual negra feminina representada no trabalho de Neusa Santos Souza e Lélia Gonzalez. As ideias de Fanon configuram-se como base para as discussões sobre relações étnico-raciais estabelecidas por essas intelectuais. Tanto Souza quanto Gonzalez, a partir e, inclusive, das experiências dialógicas no Movimento Negro no Rio de Janeiro e na academia, levantaram questionamentos imprescindíveis à construção das identidades negras, tornando-se, no caso da primeira, uma referência no estudo da vida emocional do negro e, em relação à segunda, uma voz crítica do "lugar de negro" na sociedade brasileira. Ambas trajetórias intelectuais exemplarmente convergem para a interpretação da raça, e das clivagens de gênero e classe, como fundamental condição à existência negra.
\end{abstract}

Palavras-chaves: Frantz Fanon; Neusa Santos Souza; Lélia Gonzalez; intelectuais negras; desalienação; liberdade

\begin{abstract}
The article in evidence discusses the entry of Frantz Fanon's thought in Brazil, with emphasis on the importance of the black female intellectual production represented in the work of Neusa Santos Souza and Lélia Gonzalez. Fanon's ideas are the basis for discussions about ethnicracial relations established by these intellectuals. Both Souza and Gonzalez starting with and including dialogical experiences in the Black Movement in Rio de Janeiro and in academia and raised questions essential to the construction of black identities, becoming, in the case of the first, a reference in the study of emotional life of the Negro and, in relation to the second, a critical voice of the "place of Negro" in Brazilian society. Both intellectual trajectories exemplarily converge for the interpretation of race, and of gender and class cleavages, as a fundamental condition for black existence.

\footnotetext{
${ }^{1}$ Profa. Titular do Departamento de Ciências Humanas- Campus V. da Universidade do Estado da Bahia (UNEB). Emails: rosefsilva@uneb.br ou roserosefr2000@yahoo.com.br. Agradeço imensamente a tradução do texto da língua portuguesa para a língua inglesa realizada pela Profa. Dra. Jane Anna Gordon, docente Titular do Departamento de Ciência Política, com afiliações em American Studies, El Instituto, Philosophy, and Women's, Gender, and Sexuality Studies da Universidade de Connecticut- Storrs- USA, para uma publicação especial sobre o intelectual coordenada por Nigel C. Gibson, filiado ao Emerson College, em Boston, e Professor Honorário da Unit of the Humanities na Universidade de Rhodes, África do Sul..
} 
Keywords: Frantz Fanon; Neusa Santos Souza; Lélia Gonzalez; Black intellectuals; desalienation; freedom

\section{Frantz Fanon: Uma Leitura Desafiadora}

Em 2008 Antonio Sérgio Alfredo Guimarães publica na Revista Novos Estudos o artigo intitulado A Recepção de Fanon no Brasil e a Identidade Negra. O autor elenca nesse artigo três motivos para um silêncio impactante sobre o pensamento de Fanon no Brasil. O primeiro relacionado à especificidade do bloco da esquerda latino-americana nos anos 1960. O segundo que interpreta a constituição social e nacional, sem as devidas considerações à importância da abordagem dos conflitos raciais e o terceiro que problematiza, nas universidades brasileiras, um número ainda bastante reduzido de professores e pesquisadores, declaradamente negros e ou afrobrasileiros acrescentaria, que abordem a constituição da identidade negra, a partir da crítica à condição dos sujeitos racialmente oprimidos.

Embora o clássico, Pele negra, máscaras brancas, tenha sido publicado em 1952, Guimarães afirma que a entrada do pensamento de Fanon será efetivamente marcada no Brasil, a partir da visita de Jean-Paul Sartre e Simone de Beavoir em 1960. Apesar de Guimarães afirmar que não haja registros do encontro de Sartre com Abdias Nascimento ou com qualquer outra liderança negra na década anterior, Fanon aparecerá como referência nos escritos de Nascimento em 1978, na obra intitulada $O$ Genocídio do Negro Brasileiro: processo de um racismo mascarado. Nascimento cita diretamente Fanon (NASCIMENTO, 1978, p. 44-45), desmistificando o racismo e classificando o racista como "um propósito assombrado pela má consciência", nas palavras de Fanon. Em várias passagens do texto de Abdias Nascimento, é nítida a compreensão do autor sobre o conhecimento das ideias de Fanon para a interpretação da discussão racial no Brasil.

As conferências de Sartre no Brasil, ainda segundo Guimarães, abarcaram a discussão sobre o colonialismo e as lutas de independência dos Povos do Terceiro Mundo e não a raça. Para a época, a compreensão das relações raciais não se constituía de maneira independente, demonstrava, no entanto, estar encoberta pelos estudos da ascensão de classe do negro brasileiro. No imaginário social brasileiro acreditava-se que, ao ascender socialmente, o negro seria integrado à sociedade de classes e a raça não seria para ele um impedimento a sua mobilidade. Contrariando essa ideia, o 
sociólogo Florestan Fernandes (1965), no livro A integração do negro na sociedade de classes: no limiar de uma nova era, contestou veementemente que a ascensão social do negro e do mulato pudesse representar a inexistência de preconceito e discriminação raciais e, consequentemente, do racismo:

É preciso que se tenha em mente que a mobilidade social não constitui em si mesma, índice da inexistência de preconceito e de discriminação raciais. Além disso, na situação que nos compete investigar, surpreendemos as condições e os efeitos dos mecanismos sociais de ascensão de uma categoria racial no momento mesmo em que entra em crise final todo um sistema de dominação racial. Portanto, será normal que o lôdo suba à tona. O que antes podia ser dissimulado ou encoberto, precisa vir à luz, para elevar-se à esfera da consciência, da discussão e da crítica. (FERNANDES, 1965, p. 135)

Um outro ponto importante na discussão de Guimarães, que indica contato dos intelectuais brasileiros com a leitura de Frantz Fanon, recai sobre o exílio. É no exílio que intelectuais brasileiros como Abdias Nascimento, Clóvis Moura, Octavio Ianni e Paulo Freire terão mais proximidade com os efeitos da discussão sobre alienação, situação colonial e a perspectiva política de dominação colonialista problematizadas por Fanon. E mais importante ainda é a constatação de Guimarães sobre a obrigatoriedade da leitura de Fanon nas classes de nível superior. Ele afirma que essa obrigatoriedade só acontecerá com o retorno desses intelectuais exilados ao Brasil e às universidades brasileiras em 1980.

No prefácio à edição brasileira de Pele negras, máscaras brancas, publicado em 2008, Lewis R. Gordon menciona o trabalho de Paulo Freire e cita Pedagogia do Oprimido como o resultado de uma leitura cuidadosa de Freire em relação às ideias de Fanon:

Houve uma época em que um professor universitário norte-americano que tentasse abordar a obra de Frantz Fanon em um ambiente acadêmico estaria sujeito a perder o emprego. Naqueles anos turbulentos das décadas de 1960 e 1970, a situação era diferente na América do Sul. No Chile, por exemplo, as ideias de Fanon estavam sendo ensinadas nas salas de aula, e uma leitura cuidadosa da Pedagogia do Oprimido de Paulo Freire revela o quanto essa obra sofreu influência de Fanon. Nos anos 1990 era possível estudar Fanon e Freire em cursos como Teologia Política, Filosofia da Libertação e Pensamento Social Político, e os estudiosos em todo o mundo estão agora compreendendo a relação entre Fanon e outros intelectuais brasileiros como Alberto Guerreiro Ramos e Abdias do Nascimento.

(GORDON In FANON, 2008, p. 11)

A Pedagogia do Oprimido resume a ideia de que ninguém melhor do que os oprimidos entenderá o significado da violência de uma sociedade opressora. Só a consciência crítica abre 
caminho para a verdade e para a liberdade, promovendo, dessa forma, engajamento no esforço da transformação da realidade concreta e objetiva. A revolução virá pelo conhecimento da história e pelo compromisso com a libertação das mentes, objetivando uma educação progressista em que cidadãos sejam criticamente formados e que atuem para transformar a ordem social, econômica e política, considerada por Freire, injusta.

Um dado importante no artigo de Antonio Sérgio Guimarães é afirmação da publicação de Pele negras, máscaras brancas, pela editora Fator, em Salvador, em 1983, coincidir com o que a pesquisadora Florentina da Silva Souza (2005) constata sobre Fanon ser um dos autores recomendados pelo Movimento Negro Unificado (MNU) para leitura e formação de seus ativistas e militantes. O ano de 1983 também coincide com a publicação do livro Tornar-se negro: as vicissitudes da identidade do negro brasileiro em ascensão social, escrito por Neusa Santos Souza. Esse trabalho da intelectual e militante do Movimento Negro Unificado, na época mencionada, no Rio de Janeiro, pode ser considerado uma influência significativa da leitura dos textos de Fanon. O livro floresceu como estudo da experiência emocional do sujeito negro em ascensão social e em tensão com as contradições e ambiguidades da afirmação identitária negra.

$\mathrm{Na}$ verdade, os textos de Fanon circulam, com caráter pedagógico, entre militantes e ativistas do movimento negro desde meados da década de 1960, conforme sinaliza Guimarães no mesmo artigo. Os condenados da terra, por exemplo, publicado em 1968, será referência para os estudantes negros. Principalmente para aqueles interessados em discutir a violência do mundo colonial e os processos de dominação que decorrem da colonização e que incidem diretamente sobre o modo como colonizador e colonizado se veem. O leitor é severamente levado a refletir sobre a importância da descolonização como questionamento integral da situação colonial.

Outra intelectual negra, militante do Movimento Negro Unificado, que sofreu clara influência das ideias de Frantz Fanon no seu trabalho, foi Lélia Gonzalez. Lélia, de acordo com os pesquisadores Alex Ratts e Flávia Rios, familiarizada com o pensamento de Fanon na diáspora negra, chegou a formular recomendações sobre os principais livros do intelectual publicados no Brasil:

Numa outra linha de pensamento, mas pondo o dedo na ferida da alienação do negro, encontra-se a dramática figura de Frantz Fanon, o jovem psiquiatra que se destacou na guerra da independência da Argélia. Crítico da noção de negritude, escreveu Os condenados da terra e Pele negra, máscaras brancas. Este último é uma das mais acuradas análises dos mecanismos psicológicos que induzem o colonizado e se identificar com o colonizador. $\mathrm{Na}$ sua perspectiva, a desalienação do negro está diretamente vinculada à tomada de 
consciência das relações socioeconômicas. Sua posição, crítica diante do que considerava como acomodação de seus conterrâneos para com a política assimilacionista francesa, o levou a exigir que após a sua morte fosse enterrado na Argélia. E assim foi feio (GONZALEZ In RATTS; RIOS, 2010, p.142)

Um dos principais argumentos desenvolvidos por Guimarães sobre a falta de estudos mais aprofundados no Brasil relacionados à importância do pensamento de Frantz Fanon na academia, gira em torno da pouca presença de negros nas universidades brasileiras. Guimarães, no texto apresentado, historiciza entre 1960 e início dos anos 1980 como efetivamente Fanon passa a ser referência, tanto utilizada por militantes dos movimentos negros, quanto por intelectuais brasileiros na crítica ao racismo e a todas as suas implicações com o colonialismo.

Embora o argumento seja bem construído através de exemplos de passagens elencadas que citam Fanon como singulares no trabalho dos autores pesquisados, fica claro no caminho percorrido sobre a entrada do pensamento de Fanon no Brasil, como os intelectuais brasileiros não mergulham profundamente no pensamento de Fanon como instrumento de combate ao colonialismo e, sobretudo, de questionamento às identidades negras. Em contrapartida, os intelectuais negros, que tiveram incursão no movimento e na militância negra, utilizaram Fanon como leitura obrigatória para a desmistificação de que no Brasil não há problema racial. E nesse contexto, destaca-se o trabalho da psiquiatra e psicanalista Neusa Santos Souza.

Neusa Santos Souza fez parte de uma militância negra intelectualizada, caracterizando uma fase importante entre Movimento Negro e a academia. Para o autor Borges Pereira (1981), essa fase se constituiu como fundamentalmente relevante na inserção das discussões que ocorriam no seio do movimento negro da década de 1970 na academia brasileira. Pela primeira vez, o negro deixava de ser exclusivamente objeto de estudos das ciências e passava a ser sujeito de suas próprias reflexões e produções acadêmicas nas universidades.

Contribuíram significativamente para a introdução das discussões raciais, seguidas das intersecções de classe e gênero na academia, as intelectuais negras Lélia Gonzalez, Beatriz Nascimento e Neusa Santos Souza. Segundo o pesquisador Alex Ratts (RATTS In PEREIRA; SILVA, 2009), apesar da interrupção precoce que tiveram suas trajetórias acadêmicas por motivo de doença grave, assassinato ou suicídio, o trabalho dos ativistas e intelectuais atuantes no movimento negro e na academia nessa fase acabaram por constituir "novos sentidos ao fazer político, social, racial e de gênero”. 
Neusa Santos Souza teve a sua trajetória intelectual interrompida pelo suicídio. Em 20 de dezembro de 2008, a intelectual lançou-se do alto do edifício, onde vivia, em Laranjeiras, no Rio de Janeiro aos 60 anos de idade: "suicidou-se sem antes jamais ter dado sinais de depressão ou de que pudesse um dia recorrer ao gesto extremo de tirar a própria vida [...] deixou apenas uma pequena mensagem pedindo desculpas aos poucos amigos do peito por sua decisão radical" (HERKENHOFF, 2009). A intelectual não era casada, não tinha filhos e colecionava objetos de arte plástica. Apesar da importância do trabalho de Neusa Santos Souza, sua morte foi pouco divulgada na época pelos meios de comunicação. Há, no entanto, registro de uma nota breve da Fundação Palmares sobre o fato ${ }^{2}$.

O trabalho de Neusa Santos Souza pode ser considerado pioneiro na contribuição da intelectual aos estudos da psiquiatria, psicanálise e a psicologia. A autora claramente se valeu de um método de investigação de pesquisa com pacientes chamado de social theraphy, terapia social, baseado na maneira como Frantz Fanon buscou transformar a relação entre médico e alienados. $\mathrm{O}$ método utilizado por Neusa, em semelhança ao de Fanon, levava o indivíduo ao questionamento das subjetividades negras, através do enfretamento com os dilemas implicados na ascensão de classe quando essa ocorria. O indivíduo negro descobria que, ao ascender socialmente, não estaria livre dos problemas raciais porque:

A raça, como atributo social e historicamente elaborado, continua a funcionar como um dos critérios mais importantes na distribuição de pessoas na hierarquia social. Em outras palavras, a raça se relaciona fundamentalmente com um dos aspectos da reprodução das classes sociais, isto é, a distribuição dos indivíduos nas posições da estrutura de classes e dimensões distributivas da estratificação social. (GONZALEZ; HASENBALG, 1982, p. 89)

Diferente das teorias racistas do século XIX, a raça é entendida hoje como uma construção social. O embranquecimento parecia ser, ainda nos anos 80 no Brasil, a "solução" para negros que ascendiam socialmente serem inclusos nos diferentes grupos. O trabalho de Neusa Santos Souza evidencia exatamente os aspetos dolorosos na vida emocional do sujeito negro entre embranquecerse, para ser socialmente aceito, e assumir a sua identidade negra sem negar suas subjetividades.

${ }^{2}$ Disponível em http://www.palmares.gov.br/?p=3166 


\section{Neusa Santos Souza: \\ Intelectual Negra Referência no Estudo da Vida Emocional do Negro no Brasil}

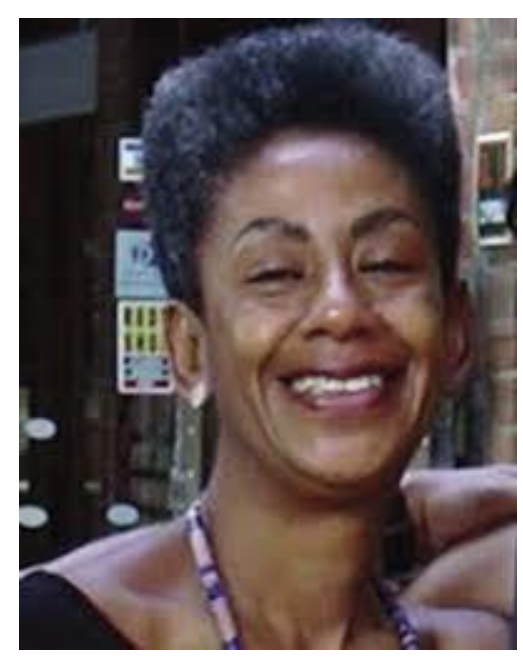

Figura 1.

Foto de Neusa Santos Souza ${ }^{3}$

Ao tratar da questão racial ou racismo no Brasil, existe uma pré-disposição nos trabalhos acadêmicos em deixar de fora o pensamento das intelectuais negras. Passa-se ao largo das produções femininas e negras nas análises ou são apenas produções citadas como mera composição discursiva, mas não como acervo relevante de contribuição às ideias em debate.

É com base nessa observação que trago à cena o livro Tornar-se negro: as vicissitudes da identidade do negro brasileiro em ascensão social, escrito pela psiquiatra e psicanalista Neusa Santos Souza, na década de 80, como resultado de sua dissertação de mestrado, que acabou se tornado referência para os estudos de psicanálise e psicologia com enfoque na persona negra. Antes de enveredar pela abordagem do texto propriamente dito, gostaria de introduzir alguns dados biográficos relevantes para situar a trajetória intelectual da escritora no contexto.

Neusa Santos Souza nasceu em 1948, na cidade de Cachoeira, no Recôncavo Baiano, cursou medicina na Faculdade de Medicina na Universidade Federal da Bahia. No início da década de 1970 teve a experiência de trabalhar em uma clínica de saúde mental no Largo da Lapinha, como

\footnotetext{
${ }^{3}$ A foto de Neusa Santos Souza está disponível em http://www.rio.rj.gov.br/documents/73801/ad6a6c41-8b70-4775b5c3-999c359e5f24 . Nesse site, encontra-se publicado um Boletim da Atenção Psicossocial Carioca pela Prefeitura da cidade do Rio de Janeiro em dezembro de 2018. O material traz uma matéria específica sobre Neusa Santos Souza e a foto da autora aqui utilizada acompanha o texto mencionado.
} 
assistente de Ana Rocha. Através da experiência com os pacientes dessa clínica, as pesquisadoras puderam avançar na organização de grupos de estudos, como por exemplo, o Grupo de Estudos Psicanalíticos (NEP). O grupo tinha como finalidade a discussão da psicanálise na Bahia junto com o intercâmbio de psicanalistas de diferentes partes do Brasil. Aconselhada por outros psicanalistas da época, Neusa Santos Souza mudou-se para o Rio de Janeiro no intuito de melhor desenvolver e ampliar os estudos sobre psicanálise, colocando, dessa forma, em prática suas experiências de trabalho iniciadas em Salvador, Bahia.

No final da década de 70, Neusa Santos Souza fez parte de um grupo de estudos do IBRAPASI- Instituto Brasileiro de Psicanálise, fundado em 1978. O grupo agregava representações de sindicatos, partidos políticos e comunidade de base. A investida intelectual de Neusa na psicanálise acontecia mais pelo contato com psicanalistas à margem da corrente dominante da época. Outro aspecto importante no período, em relação a trajetória em evidência, diz respeito à participação da autora nos movimentos negros no Rio de Janeiro e, consequentemente, o contato com lideranças negras que impulsionaram Neusa Santos Souza buscar discussões mais críticas sobre África, diáspora africana e positividade da identidade étnico-racial que pudessem contribuir para suas pesquisas ${ }^{4}$.

A relação da intelectual com o Movimento Negro é importante para a compreensão sobre o lugar que a sua produção teórica ocupa. É através da experiência de militância nos movimentos negros que os intelectuais negros pedagogicamente desenvolvem suas pesquisas, suas ações políticas e seus projetos de intervenção intelectual. É no Movimento Negro que o debate sobre o racismo marca significativamente a relevância da politização da raça e dos modos de operação da ideia de raça para a construção de identidades étnico-raciais no plano individual e coletivo. Para a pesquisadora Nilma Lino Gomes, o Movimento Negro educador, denominação utilizada na identificação do movimento como "produtor de saberes emancipatórios e um sistematizador de conhecimentos sobre a questão racial no Brasil” (GOMES, 2017, p.14), trouxe para o âmbito de suas discussões abordagens diretamente relacionadas à interpretação urgente do racismo no contexto social brasileiro.

\footnotetext{
${ }^{4}$ Algumas informações biográficas da autora Neusa Santos Souza foram pesquisadas na dissertação de mestrado intitulada "Escrevivências das memórias de Neusa Santos Souza: apagamentos e lembranças negras nas práticas PSIS" (PENNA, 2019).
} 
Conforme referenciado por Lélia Gonzalez, no livro Lugar de negro, o estudo citado de Neusa Santos Souza representa "importante trabalho sobre o drama de ser negro no Brasil, tais mecanismos de ocultamento e negação são devido ao fato de, em termos psicanalíticos, o branco ser vivenciado como ideal do ego". (GONZALEZ; HASENBALG, 1982, p. 54-55). Pela maneira como Lélia faz referência ao trabalho de Neusa fica evidente o contato que as duas intelectuais tiveram a partir da militância no Movimento Negro no Rio de Janeiro, desempenhando juntas um protagonismo feminino e negro fundamental para o aprofundamento crítico da consciência racial ${ }^{5}$.

\section{"Tornar-se Negro": os Efeitos do Discurso Sobre Si do Sujeito Negro numa Sociedade Branca}

A decisão de abordar o livro Tornar-se negro: as vicissitudes da identidade do negro brasileiro em ascensão social, escrito por Neusa Santos Souza e publicado em 1983, tem caráter pedagógico, de levar ao conhecimento, de todos os interessados em discutir as relações raciais no Brasil, uma análise mais aprofundada e relacionada aos principais problemas emocionais do sujeito negro em ascensão.

Até onde a violência do racismo provoca, especificamente no negro em ascensão, um comportamento de redução a um modelo branco e de total rejeição à construção e afirmação da identidade negra, confluindo para o que Frantz Fanon denomina de patologia? O estudo tem absoluta relevância porque ilustra, na sua metodologia, as experiências vividas por indivíduos negros em situação de enfrentamento com a sua própria capacidade de resistência a um Ideal do Ego que seja branco. A saída, conforme aponta a autora, repousa numa atitude mais politizada sobre a transformação da História e da história.

Em 1981, a autora defendeu a sua dissertação de mestrado em Psiquiatria no Curso de PósGraduação do Instituto de Psiquiatria da Universidade Federal do Rio de Janeiro, trabalho que culminou com o estudo sobre o tornar-se negro. A dissertação de mestrado e, posteriormente o livro intitulado Tornar-se negro: as vicissitudes da identidade do negro brasileiro em ascensão social, significou, segundo o prefácio de Jurandir Freire Costa, uma reflexão sobre violência:

\footnotetext{
${ }^{5}$ Interessante observar que o livro Lugar de negro é publicado em 1982 e o livro Tornar-se negro: as vicissitudes da identidade do negro brasileiro em ascensão social em 1983. A citação de Lélia Gonzalez ao trabalho de Neusa Santos Souza em 1982 reforça uma aproximação evidente entre essas duas mulheres negras e intelectuais, que desafiaram enfrentar, no momento mais agudo de silenciamento e repressão, os seus efeitos psicológicos, patologizantes do racismo no Brasil.
} 
A violência parece-nos a pedra de toque, o núcleo central do problema abordado. Ser negro é ser violentado de forma constante, contínua e cruel, sem pausa ou repouso, por uma dupla injunção: a de encarnar o corpo e os ideais do Ego do sujeito branco e a de recusar, negar e anular a presença do corpo negro. (COSTA in SOUZA 1983, p. 02)

Para Jurandir Freire Costa, a repercussão da obra não foi tão expressiva na época porque psicanalistas não entendiam a questão racial como relevante para o campo de análise da psicanálise. Não entendiam os problemas decorrentes das relações raciais como um entrave para a construção da persona negra. Reconhecer estudos mais eficientes sobre histórias que caracterizam o tornar-se negro, não é aceitar o negro como problema, mas é aceitar a sua existência e, sobretudo, a sua capacidade de pensamento e de produção de ideias.

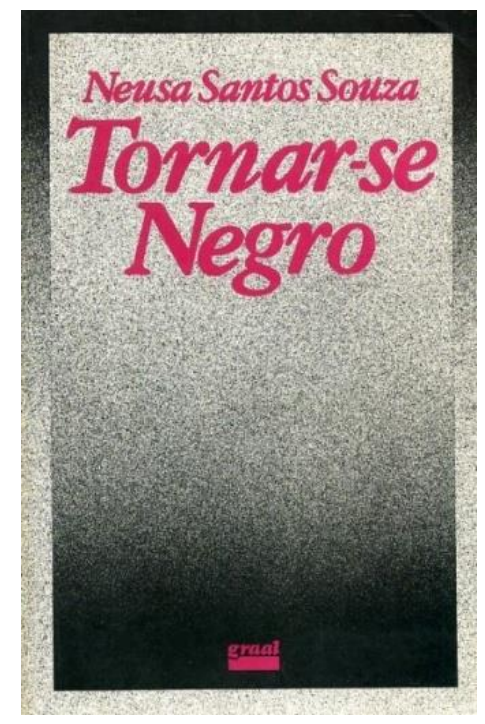

Figura 2.

Edição publicada pela Graal em $1983^{6}$

Neusa Santos Souza trouxe para o campo da psicanálise os efeitos de uma forma de análise baseada no conhecimento dos relatos das experiências negras. Relatos de histórias de vida e, ao mesmo tempo, da tentativa de compreensão dessas histórias, a partir de um discurso do sujeito negro sobre si mesmo. O principal questionamento na metodologia de trabalho de Souza

\footnotetext{
${ }^{6}$ Foto da capa do livro de Neusa Santos Souza disponível em https://www.geledes.org.br/racismo-por-que-se-matoupsicanalista-negra-que-fazia-sucesso-no-rio/
} 
correspondeu identificar, através do estudo de caso $^{7}$ e a técnica da história de vida ${ }^{8}$, os significados da experiência de ser negro numa sociedade branca.

Quais são os efeitos do discurso sobre si? Em síntese, os relatos colocam o sujeito negro em primeira pessoa. A persona negra concentra, em seu discurso, relatos particulares e em primeira pessoa, sobre as particularidades das relações consigo e com aqueles no seu entorno. A linguagem empregada nos depoimentos traduz uma forma de pronúncia sobre fatos, que teoricamente passariam no âmbito social sem muita importância, mas que, ao serem narrados por uma voz negra, produzem elementos de análise que problematizam a existência do racismo e da violência de viver num mundo de negação à experiência negra. Este conjunto de vozes compõem um material potencialmente rico porque é a partir dele que toda as análises são construídas na obra. São essas vozes, através da materialidade discursiva, que captam as contradições e ambiguidades do tornarse negro.

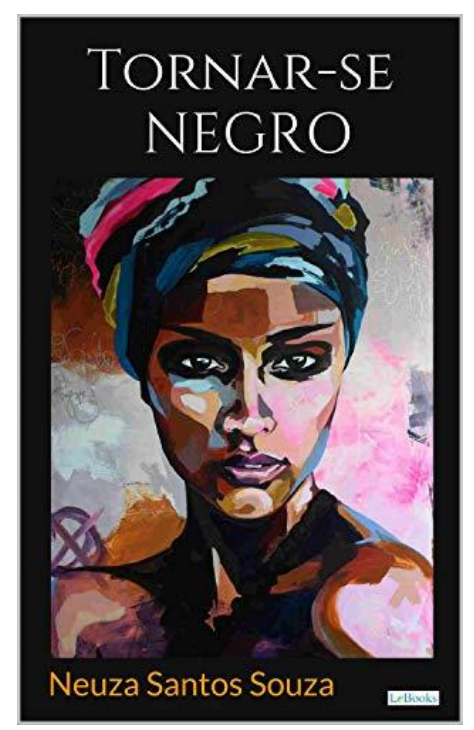

Figura 3.

Edição publicada LeBooks.com.br ${ }^{9}$

\footnotetext{
${ }^{7}$ Para Neusa Santos Souza o estudo de caso é definido no estudo como: "método qualitativo de análise onde qualquer unidade social é tomada como representativa da análise". (SOUZA, 1983, p.69)

${ }^{8}$ Sobre as "histórias de vida", a autora explica: "Esta técnica tem uma tradição nas ciências sociais, particularmente na Antropologia. Mais recentemente a Psiquiatria e a Psicanálise tem se utilizado das autobiografias para o estudo aprofundado do seu objeto. Para citar apenas um exemplo, investido de maior relevância e significação, lembramos que Freud elaborou a teoria da paranóia com base no relato autobiográfico do Dr. Daniel Paul Schreber- o famoso caso Schreber" (SOUZA, 1983, p. 70-71).

9 Foto disponível em https://www.amazon.com.br/TORNAR-SE-NEGRO-Neusa-Santos-Souzaebook/dp/B07X2LXY68
} 
O livro compõe dez histórias de vidas contadas, a partir de um processo de ascensão social dos sujeitos negros, numa sociedade racista e discriminatória em suas práticas sociais. Os depoimentos recolhidos e analisados colocaram em evidência, em primeiro lugar, a violência brutalmente ininterrupta a que os corpos negros são submetidos com extrema frequência e a tentativa de negação e, até mesmo, de aniquilamento do corpo negro em detrimento de um ideal de domínio do Ego do sujeito branco. O estudo é revelador da vida emocional do negro, acompanhada dos seus dilemas, das suas angústias e de uma forma de reação ao sentimento de opressão que incide diretamente entre quem se é e quem se deseja ser numa sociedade de hegemonia branca e contraditoriamente vinculada à ideologia da democracia racial.

Durante a sessão de uma hora, as pessoas previamente escolhidas, de acordo com os critérios de ser negro, viver no Brasil e de estar em ascensão social, falavam de suas vidas. Contavam fatos diretamente relacionados aos seus afetos, intimidade, conflitos e emoções e só eram interrompidas quando algo na narrativa não ficava muito bem compreendido.

O contato inicial por telefone criou nos entrevistados a expectativa que Neusa fosse branca. Como haver interesse do negro para com o negro? De saber da relação de seus sentimentos com o "novo" entorno social promovido pela ascensão? Por que as narrativas decorrentes dessas histórias fariam sentido para estudo da persona negra? A metodologia empregada pela autora no trabalho buscou colocar em questionamento que nascer com a pele preta e compartilhar a história de “desenraizamento, escravidão, e discriminação racial”, não garante consciência quanto à identidade negra.

Ser negro, para Neusa Santos Souza, é tornar-se negro de posse de um discurso acerca de si e implica um processo que pressupõe consciência política, não contraditória à fundamental importância das culturas negras e ao enfrentamento da sistemática presença da discriminação racial e do racismo na esfera social.

Ser negro é, além disso, tomar consciência do processo ideológico que, através de um discurso mítico acerca de si, engendra uma estrutura de desconhecimento que o aprisiona numa imagem alienada, na qual se conhece. Ser negro é tomar posse dessa consciência e criar uma nova consciência que reassegure o respeito às diferenças e que reafirme uma dignidade alheia a qualquer nível de exploração. (SOUZA, 1983, p. 77)

Neusa Santos Souza é categórica ao justificar a importância do trabalho. Ela afirma que existe uma precariedade de estudos a respeito da vida emocional dos negros no Brasil. A autora 
demonstra, no primeiro capítulo, ou seja, na introdução do texto, que optou por percorrer na linha investigativa do cientificismo a emoção desprezada do sujeito negro "paciente". Ao optar por essa forma de investigação científica, em que o discurso sobre si é imprescindível ao conhecimento de si, compreender o significado de ser negra, nesse processo de investigação na condição de mulher, psiquiatra, psicanalista e pesquisadora, envolve a seguinte definição:

Saber-se negra é viver a experiência de ter sido massacrada em sua identidade, confundida em suas perspectivas, submetida a exigências, compelida a expectativas alienadas. Mas é também, e sobretudo, a experiência de comprometer-se a resgatar sua história e recriar-se em suas potencialidades. (SOUZA, 1983, p. 18)

A pergunta guia do estudo interroga qual seria o custo emocional, conforme problematiza a autora, da sujeição, negação e massacre da identidade histórico existencial negra? Dois caminhos são possíveis: um que reduz o negro a um modelo do branco, quase a uma caricatura, que nas palavras da autora, abre uma "ferida narcísica", criando, portanto, as condições de "patologia do negro"; e o outro de embates com a construção de uma identidade negra enquanto tarefa eminentemente política que brota da contestação do modelo branco a ser seguido. Em ambos os casos, o componente emocional está presente e traz à tona as dificuldades, os conflitos e os enfrentamentos, com os quais a experiência da existência negra tem que demasiadamente lidar para ser, sabendo-se negro.

Ao traçar, no segundo capítulo, os antecedentes históricos da ascensão social do negro brasileiro, demostrando a construção da emocionalidade negra, a autora confirma que a emocionalidade é uma construção histórica subordinada à história da formação social, em que o negro, mesmo depois da desagregação da sociedade escravocrata e da substituição pela sociedade capitalista, continuou sendo inferiorizado e submisso ao modelo de identidade baseado na brancura. Ainda na visão da autora, a raça, enquanto noção ideológica, foi engendrada como critério social para a distribuição da posição da estrutura de classes. E neste sentido, o projeto de ascensão social, cujo tripé correspondia a cor, a ideologia do embranquecimento e a democracia racial, passou a ser estruturante das relações raciais no Brasil e uma possibilidade de inserção social do negro, considerado disciplinado, dócil, submisso e útil. Acreditava-se que a inserção social de negros no Brasil aconteceria, à medida que a ascensão social fosse concretizada, na fragmentação/ negação da identidade negra e na assimilação aos padrões brancos das relações sociais. 
No terceiro capítulo, ao tratar do mito negro, a autora primeiro define mito como: "faladiscurso- verbal ou visual- forma de comunicação sobre qualquer objeto: coisa, comunicação ou pessoas" (SOUZA, 1983, p. 25). Ela acrescenta à discussão que o mito tem um efeito social e que pode ser entendido na convergência das determinações econômicas, políticas, ideológicas e psíquicas. Daí em diante, o caminho explorado pela pesquisadora é explicativo e discorre sobre a forma como o mito negro é forjado para produzir a singularidade do "problema" negro.

O mito negro, a partir do que Neusa Santos Souza chama de "singularidade tridimensional", se impõe como um desafio à submissão. Um desafio à contestação da mensagem ideológica que rompe com a identificação do negro com tudo que é irracional, feio, ruim, sujo, sensitivo, superpotente e exótico. Ainda no segundo capítulo, a autora se vale de uma sequência de trechos extraídos das histórias de vida dos participantes da pesquisa para análise e uma, em particular, chama atenção. Àquela que faz menção à maneira como sujeitos negros devem se impor, no sentido de evitar à violência diária a que são expostos.

Mas como se impor? A autora faz referência ao pensamento de Frantz Fanon para endossar que, ao viver no mundo dos brancos, o negro deixa de se comportar como um indivíduo de ação. Neusa busca formular suas argumentações a partir do texto de Fanon intitulado Escucha, blanco! A pesquisadora cita Fanon diretamente para explicar: "El negro tiene duas dimensiones. Una com su congénere, otra con el branco. Um mismo negro se comporta de modo diferente con um blanco y con otro negro". (FANON in NEUSA, 1983, p. 27). Na opinião da autora, ao conviver com o branco, a marca da desigualdade expressa na convivência com a diferença é introjetada pelo negro e, ao mesmo tempo, também reproduzida por ele na convivência com o seu grupo étnico-racial. Isso explicaria o fato de ao ascender socialmente, negros passariam, com os brancos, a serem racionais e com os negros, emocionais.

O perigo, salienta a autora, é a reprodução, pelo negro, do discurso do branco. Em trechos de parte das histórias contadas, o que se pode perceber é que existe uma eficácia dos "mecanismos ideológicos" que, em nível psíquico, atua para que o negro seja um "sujeito sujeitado", conforme discute a autora:

Passaram por nossos olhos, ouvidos e pele, fragmentos de discursos, colhidos das históriasde-vida dos nossos entrevistados, onde ouvimos falar o negro enquanto sujeito que introjeta, assimila e reproduz, como sendo seu, o discurso do branco. O discurso e os interesses. Tal façanha- a hegemonia dos interesses dominantes- é valorizada pela eficácia dos mecanismos ideológicos cuja garantia, a nível psíquico, é assegurada por certas articulações estruturais e transações psicodinâmicas que cumpre elucidar. Assim é que se impõe o exame 
de dois conceitos fundamentais- Narcisismo e Ideal do Ego ${ }^{\mathbf{1 0}}$ - forças estruturantes do psiquismo que desempenham um papel chave na produção do negro enquanto sujeito sujeitado, identificado e assimilado ao branco. (SOUZA, 1983, p. 32)

O conceito, Ideal do Ego, destacado por Neusa Santos Souza, comporá a fundamentação do quarto capítulo. Nesse capítulo, a autora afirma que o Ideal do Ego é modelo de construção para o indivíduo, baseado em modelos anteriores representados pelos pais, responsáveis e etc. $\mathrm{O}$ Ideal do Ego pode ser caracterizado de três formas: ideal- perfeito ou quase e interpretado como uma instância que estrutura o sujeito psíquico.

O negro trazido à discussão pela pesquisadora está diretamente relacionado com aquele que vive uma ideologia imposta pelo branco como ideal, cujo Ideal do Ego, é branco. Neste ponto da discussão, o estudo de Neusa Santos Souza aproxima-se muito da concepção da "dupla consciência” em W.E.B. Du Bois para a formação psicológica dos dois lados do ser negro. Para Du Bois, a dupla consciência corresponde à negrificação desenvolvida por um processo de racialização comum ao sistema colonial. Através dos olhos do opressor, o oprimido percebe-se de duas formas: a primeira, cuja habilidade permite ao oprimido ver-se com os seus próprios olhos e a segunda, que elimina esse primeiro olhar do oprimido sobre si e pontencializa um segundo, baseado na forma como o colonizador enxerga o colonizado. Esse segundo olhar torna-se crítico porque tende a desracializar a identidade do sujeito oprimido e a categorizá-lo dentro de um outro processo, o da assimilação (DU BOIS, 1903) ${ }^{11}$.

Mas o questionamento imprescindível ao entendimento da constatação interroga: como se constrói o Ideal do Ego negro? Segundo a autora, primeiro, através da negação e expurgo do que ela chama de "mancha negra". E depois, de acordo com esse raciocínio, a negação pode provocar a rejeição do próprio corpo físico, seguida por atos de violência que se manifestam de forma rápida e brutal, com o objetivo de causar ao corpo o dano, às vezes, irreversível.

O contexto familiar é identificado, pela autora, como lugar primeiro onde a ação constituinte do Ideal do Ego se desenrola. Outros contextos na vida dos entrevistados acabam

\footnotetext{
${ }^{10} \mathrm{O}$ destaque em negrito foi por mim atribuído ao texto da autora. Os conceitos destacados são de fundamental importância para a compreensão do exame, em nível psíquico, do que se considera "patologia do negro".

${ }^{11}$ Conferir em Trajetórias de Dois Intelectuais Negros: Abdias Nascimento e Milton Santos. Tese (Doutorado no Programa Multidisciplinar de Pós-Graduação em Estudos Étnicos e Africanos) - Faculdade de Filosofia e Ciências Humanas da Universidade Federal da Bahia. Salvador, p. 233, 2010.
} 
sendo igualmente importantes e são exemplificados a partir das experiências da vida na rua, na escola, no trabalho e nos espaços de lazer.

A relação entre Ego e Ideal do Ego está em constante tensão por conta da pressão que o Superego exerce no Ego, em busca de um ideal inalcançável, de um ideal de identidade com o Ego Ideal. Essa experiência, acrescenta a autora, não é prerrogativa somente de negros. É uma experiência que pode ser vivenciada por todo sujeito não psicótico. Nas experiências de vida que orientaram o trabalho destacado, observou-se também que entre o Ego atual e o Ideal do Ego existe uma considerável insatisfação em relação as consequências das possíveis conquistas do sujeito negro. Na busca por uma afirmação, tentando compensar o "defeito" da cor, ser melhor, no caso do sujeito negro, nunca é suficiente para a garantia do êxito porque "o Ideal do Ego do negro, que é em grande parte construído pelos ideais dominantes, é branco. E ser branco lhe é impossível” (SOUZA, 1983. 40).

Ao se dar conta da impossibilidade de realizar o Ideal, o estudo mostra que o negro vislumbra duas alternativas genéricas: a primeira, cuja tendência é sucumbir às punições do Superego e, a segunda, que o empurra para a busca de saídas. Ao sucumbir às punições do Superego, a melancolia aparece como estado mórbido caracterizado pelo abatimento mental e físico que pode manifestar problemas distintos, incluindo, o sentimento de perda da autoestima que, enquanto condição psicopatológica, denuncia a falência do Ego. Entre o ideal e o possível, vários sentimentos, segundo a autora, são desencadeados pelo sujeito negro (referência ao grupo entrevistado) ao longo desse processo, tais como: "culpa, inferioridade, insegurança, angústia, timidez, retraimento, ansiedade fóbica, autodesvalorização, conformismo, atitude fóbica e submissão". As experiências vividas pelos entrevistados, cujo Ego caiu em "desgraça", a partir do domínio desses sentimentos, colaboram para que se sintam, em geral, "humilhados, intimidados e decepcionados" por não poderem corresponder às expectativas de um Ideal de realização do Ego.

A outra alternativa está diretamente relacionada à luta para encontrar um caminho que possa ser substituto do "Ideal irrealizável". Essa luta, conforme identificado nas entrevistas realizadas, está, na maioria das vezes, associada à busca de um objeto amoroso - meio de satisfação do narcisismo -, como por exemplo, “o amor autêntico". Um amor, cujo parceiro branco e ou a parceira branca, através da intimidade da relação afetiva sexual, motive no sujeito negro a identificação para a realização do "Ideal do Ego inatingível". Aqui, pontua a autora, ao fazer referência a Fanon, ama-se a brancura e, sendo assim, ela acrescenta: 
O negro que elege o branco como Ideal do Ego ${ }^{12}$ engendra em si mesmo uma ferida narcísica, grave e dilacerante, que, como condição de cura demanda ao negro a construção de um outro Ideal de Ego. Um novo Ideal de Ego que lhe configure um rosto próprio, que encarne seus valores e interesses, que tenha como referência e perspectiva a História. Um Ideal construído através da militância política, lugar privilegiado da construção transformadora da História. (SOUZA, 1983, p. 44)

Na concepção de Neusa Santos Souza, o exercício da prática política, no caso do sujeito negro, se representa como forma de recuperação da autoestima. É através da prática política, de entendimento e capacidade de articulá-la aos entremeios da história, que sujeitos negros passam a afirmar a sua existência e a marcar o seu lugar de protagonistas na construção da identidade negra.

No quinto capítulo, a autora investe no relato da história de Luísa. É a única história que aparece completa no livro. Através dos fatos narrados, ficam evidentes as relações de Luísa com a família, com os amigos da escola e com os "amores" e, por conseguinte, os sentimentos, a princípio, mais de rejeição, do que de identificação com o ser negra, vão compondo a narrativa. E daí por diante, toma-se conhecimento das dificuldades de enfrentamento com a identidade negra e, sobretudo, das dúvidas, incertezas e dores, até mesmo, no corpo físico, que Luísa vivencia na sua trajetória. A história de Luísa é interpretada pela autora da seguinte maneira:

Luísa logra conquistar uma identidade de mulher negra. Sua identidade, construída de mitos e imagos, estrutura-se como história: é um sistema opaco de desconhecimento e reconhecimento, marcado por todas as ambiguidades provenientes de sua origem imaginária. Identidade feita de contradições, submetida às formações ideológicas dominantes e sobredeterminadas pela história individual e pela História da formação social onde a primeira se inscreve. É com esta identidade que Luísa toma consciência de suas contradições e tenta participar da luta política que busca transformar a História e sua história. (SOUZA, 1983, p. 59)

O protagonismo de Luísa, na conquista de sua identidade negra, vem de um processo, conforme problematiza Frantz Fanon, de desalienação do próprio ser. De reflexão, através do curso da História, sobre a situação social do negro, no contexto da dominação pelo homem branco, e do racismo implicado na violência dessa relação. $\mathrm{O}$ conhecimento da História e das imagens de representação do sujeito negro exigem, do próprio sujeito negro, o que Fanon denomina de "tomada de consciência".

\footnotetext{
${ }^{12}$ Grifo meu.
} 
A tomada de consciência proposta por Fanon, e direcionada aos negros, propõe uma leitura da realidade racial que os leve a uma escolha entre uma situação "autêntica" ou "inautêntica" do comportamento negro. Com Luísa, não foi diferente! As ambiguidades e contradições, relacionadas à afirmação da identidade negra que aparecem coladas à narrativa da história pessoal de Luísa, se atritam com o que a autora chama de "formações ideológicas dominantes". Como perceber que a história individual, no caso dos negros, está moldada a partir de uma história coletiva de opressão à existência negra?

A resposta está na proposição formulada por Fanon em Pele negras, máscaras brancas. A saída é transformar o negro em um ser de ação. E para que o sujeito negro passe consciente por esse processo de transformação e de protagonismo de suas próprias capacidades, é fundamental que ele conheça a sua história e que, através dela, encontre os pressupostos de afirmação da sua identidade racial, tornando-a centro de uma experiência de vivência ligada à maturidade da responsabilidade e do exercício de uma prática política imprescindíveis ao enfrentamento das diferentes formas de dominação impostas pelo colonialismo.

\section{Frantz Fanon e o Tornar-se Negro: Desalienação e Liberdade}

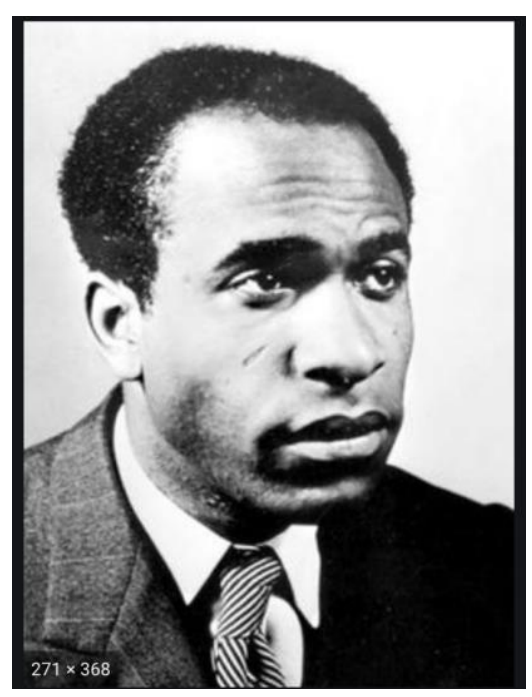

Figura 4.

Foto de Frantz Fanon ${ }^{13}$

\footnotetext{
${ }^{13}$ Foto disponível em https://en.wikipedia.org/wiki/Frantz_Fanon
} 
O trabalho de Fanon, para além do pensamento revolucionário que representa, demanda uma série de interpretações e reflexão crítica acerca dos sentidos e significados do racismo como resultado do colonialismo. Para Fanon, a violência do processo colonial é responsável pela psicopatologia do negro, conforme problematizado em Pele negras, máscaras brancas. Fanon inaugura, através da sua capacidade de análise psiquiátrica, uma forma de crítica ao mundo colonial que nos elucida a respeito das consequências psicológicas da colonização. A combinação do ativismo intelectual de Fanon, com a filosofia e com a psiquiatria, o levou seriamente ao destaque de ser um dos intelectuais mais importantes do século XX na luta anticolonial e antirracista.

Como médico psiquiatra no hospital Blida- Joenville na Argélia, instituição hoje chamada de Hospital Frantz Fanon, o intelectual revolucionário confrontou a psiquiatria clássica e estudou casos que o levaram ao profundo conhecimento da psicologia do ser negro, seus delírios, suas necessidades e suas dificuldades para viver num mundo de negação à existência negra. A técnica "social therapy" ou terapia social, traduzida como inovação científica e epistemologia lúcida, praticada com François Tosquelles e aplicada aos pacientes também “indígenas” e muçulmanos, visava transformar a relação do médico com os alienados.

A aplicação de um método diferenciado de terapia proposto por Fanon buscou compreender as dimensões da alienação mental, teoricamente consequente de uma doença psíquica, com as alterações de personalidade e da realidade dos pacientes. A violência do mundo colonial altera o devir do sujeito em sua individualidade e em sua coletividade. E a alienação, advinda dos distúrbios psíquicos e traumáticos, passa a ser um estado mental de conflito com um mundo dominante que constantemente interroga a condição humana dos dominados.

Esse estado de alienação mental está claramente tipificado nos exemplos trazidos por Neusa Santos Souza no seu livro e verticalizado na história escolhida para análise, a de Luísa. A "paciente", embora reconheça suas raízes na ancestralidade negra e, em certa medida, questione o "modelo" branco, interrogando, principalmente, a relação da mulher negra com o mundo ao seu redor, Luíza tende a reproduzir imagens, a partir de um complexo psicoexistencial de enfrentamento com a afirmação da identidade negra. Para Fanon, existe uma linguagem do negro que é definidora de características comportamentais consequentes de uma ideologia colonial. A avó de Luísa reproduzia essa linguagem: “(...) se você vir confusão, saiba que é o negro que está fazendo; se você vir um negro correr, é ladrão. Tem que casar com um branco para limpar o útero". (SOUZA, 1983, p. 46). Na história de vida contada por Luíza, existe uma tentativa de aproximação 
com um ideal de ser humano que afasta qualquer possibilidade de semelhança e ou reprodução dessa semelhança com o negro.

A história de vida de Luísa é também reflexo da solidão que mistura sentimentos como raiva e vergonha de ser negra, de não se assemelhar a um padrão de ser humano previamente estabelecido como ideal. De distanciamento de um mundo que não fala a sua linguagem e que não se identifica com a linguagem que ela tenta esboçar. As meninas, a volta de Luíza, tinham "nariz fino e cabelo liso" e ela era aconselhada, por sua mãe, a colocar "pregador de roupa no nariz pra ficar menos chato", descreve Neusa (SOUZA, 1983, p.47). O mundo exemplificado na narrativa de Luíza é totalmente desconectado de referências identitárias que pudessem trazê-la para a sua realidade, para a realidade de uma menina-mulher- negra.

A experiência vivida de Luíza, relativa à sua maturidade, será configurada, através da relação amorosa discutida por Fanon, entre a mulher de cor e o homem branco, frente ao sentimento de inferioridade que escraviza a pessoa negra. Luísa se autodenominava negra-branca porque não queria ser igual as outras pessoas negras. Tinha desprezo pelos negros e admiração pelos brancos. Seus melhores amigos eram judeus. Já parecia claro não gostar de pobres e pretos, há menos que tivesse proximidade com o referencial branco: "Para mim um homem negro tinha que ser especial. Ser muito melhor que o branco, se destacar, ser como eu. Teria que ser lindo! Muito bonito, muito inteligente. Nunca me apareceu um homem assim..." (SOUZA, 1983, p. 50). Com o seu primeiro namorado branco, Luíza nunca foi apresentada à família dele. Embora não achasse que a questão racial fosse um empecilho para a relação e, sim, a sua "feiúra", a verdade é que, conforme afirma Fanon, como saber se o sentimento de inferioridade será superado?

Neusa Santos Souza parte de uma análise da história de Luíza, no seu livro, que é, conforme recomenda Fanon, psicológica. Para o intelectual, "a verdadeira desalienação do negro implica uma súbita tomada de consciência das realidades econômicas e sociais" (FANON, 2008, p. 28). O que Fanon propõe com a desalienação? A desalienação implica em consciência e a consciência em liberdade. O processo de desalienação livraria o negro de ser interpretado como problema? A desalienação retiraria o negro do dilema colocado por Fanon: "branquear ou desaparecer". A premissa moderna da razão nega a existência negra, excluindo o negro da humanidade. O complexo negro não vem do negro, vem de fora e da maneira como o negro é socialmente interpretado:

Se ele se encontra a tal ponto submerso pelo desejo de ser branco, é que vive em uma sociedade que torna possível seu complexo de inferioridade, em uma sociedade cuja consistência depende da manutenção desse complexo, em uma sociedade que afirma 
superioridade de uma raça; é na medida exata em que esta sociedade lhe causa dificuldades que ele é colocado em uma situação neurótica. (FANON, 2008, p. 95)

A desalienação é a resposta para o não branqueamento e o não desaparecimento do sujeito negro. Em outras palavras, é aparecer, a partir de uma tomada de consciência, definida por uma nova possibilidade de existir, que liberta o negro desse complexo de inferioridade. Fanon chama atenção para o trabalho com o inconsciente no sujeito negro: "Enquanto psicanalista, devo ajudar meu cliente a conscientizar seu inconsciente, a não mais tentar um embranquecimento alucinatório, mas sim a agir no sentido de uma mudança das estruturas sociais” (FANON, 2008, p. 95).

O alienado vive o que Fanon chama de "despersonalização absoluta”, que corresponde aos efeitos de uma dominação que atinge diretamente o ser psíquico do sujeito negro. E na luta política contra todas as formas de opressão, é importante perceber que: "Lutar contra o racismo é inútil, se não se evidenciam os efeitos da opressão exercida pela cultura dominante, opressão que atinge as comunidades, o político e a cultura, mas também o psíquico" (CHERKI ${ }^{14}$ In FANON, 2005, p. 13). Fanon vai tratar das relações dominante/ dominado e as condições de libertação em Os condenados da terra. Fanon escreve a partir de uma mensagem singular e endereçada para os deserdados:

Os condenados da terra aos quais Fanon se dirigia eram os deserdados dos países pobres, que queriam realmente terra e pão, ao passo que, na época, a classe operária no mundo ocidental, muitas vezes racista e evidentemente ignorante sobre as populações além-mar, demonstrava uma relativa indiferença pelo destino das colônias de que, indiretamente, se beneficiava. (CHERKI In FANON, 2005, p. 12).

O livro, Os condenados da terra, interroga os efeitos da dominação e as consequências da submissão em relação aos povos dominados. O texto, além de ter se tornado um clássico, é um chamado plural à libertação e à "descolonização do ser". Parece que ao tratar da "desalienação" e da "descolonização", esse último termo, muitas vezes, utilizado em diferentes contextos e por alguns pesquisadores sem a devida referência ao trabalho de Fanon, o autor combina os ingredientes perfeitos para o enfrentamento com a violência engendrada no seio das culturas dominantes.

\footnotetext{
${ }^{14}$ Alice Cherki, psicanalista argelina, assinou o prefácio de Os condenados da terra da edição publicada em 2002. Cherki trabalhou com Fanon na Argélia e na Tunísia e dentre os vários livros publicados por ela, Frantz Fanon: portrait tem destaque. O livro, baseado nas lembranças da convivência da autora com Fanon, corresponde a uma leitura biográfica imprescindível ao conhecimento da trajetória de um dos mais importantes intelectuais do século XX.
} 
O que Neusa Santos Souza propõe, no final da análise da história de Luísa, é a transformação da maneira como Luíza existe para ela mesma e para o mundo, através do conhecimento que envolve a luta política do sujeito negro. A luta contra a violência do colonialismo, que funciona para manter a consistência do complexo de inferioridade do negro. $\mathrm{O}$ que está proposto por Fanon e por Neusa é o desmantelo da superioridade racial, que liberta o sujeito negro do inconsciente alucinatório e neurótico do embranquecimento, fundamentalmente mantido pelo domínio do mundo colonial.

Tanto para Fanon quanto para Souza, a violência implicada na rejeição ao corpo negro só prospera quando o sujeito negro não se dá conta que o seu corpo é a sua perspectiva no mundo (GORDON, 1997). Segundo Gordon, rememorando Sartre (1956), essa perspectiva envolve três dimensões- a dimensão de ver, a dimensão de ser visto e a dimensão de estar consciente de ser visto pelos outros. A combinação dessas três dimensões em potencial é imprescindível à noção interpretativa do sujeito negro no mundo. O corpo negro, a partir de suas subjetividades, responde que a experiência de existência é possível quando através dela criamos as condições políticas de resposta ao racismo e ao colonialismo. É contra a impossibilidade de ser negro/negra no mundo que intelectuais como Fanon e Neusa lutaram e tornaram suas ideias relevantes para as discussões sobre dominação e liberdade humana.

\section{O corpo negro de Lélia Gonzalez: a experiência do tornar-se}

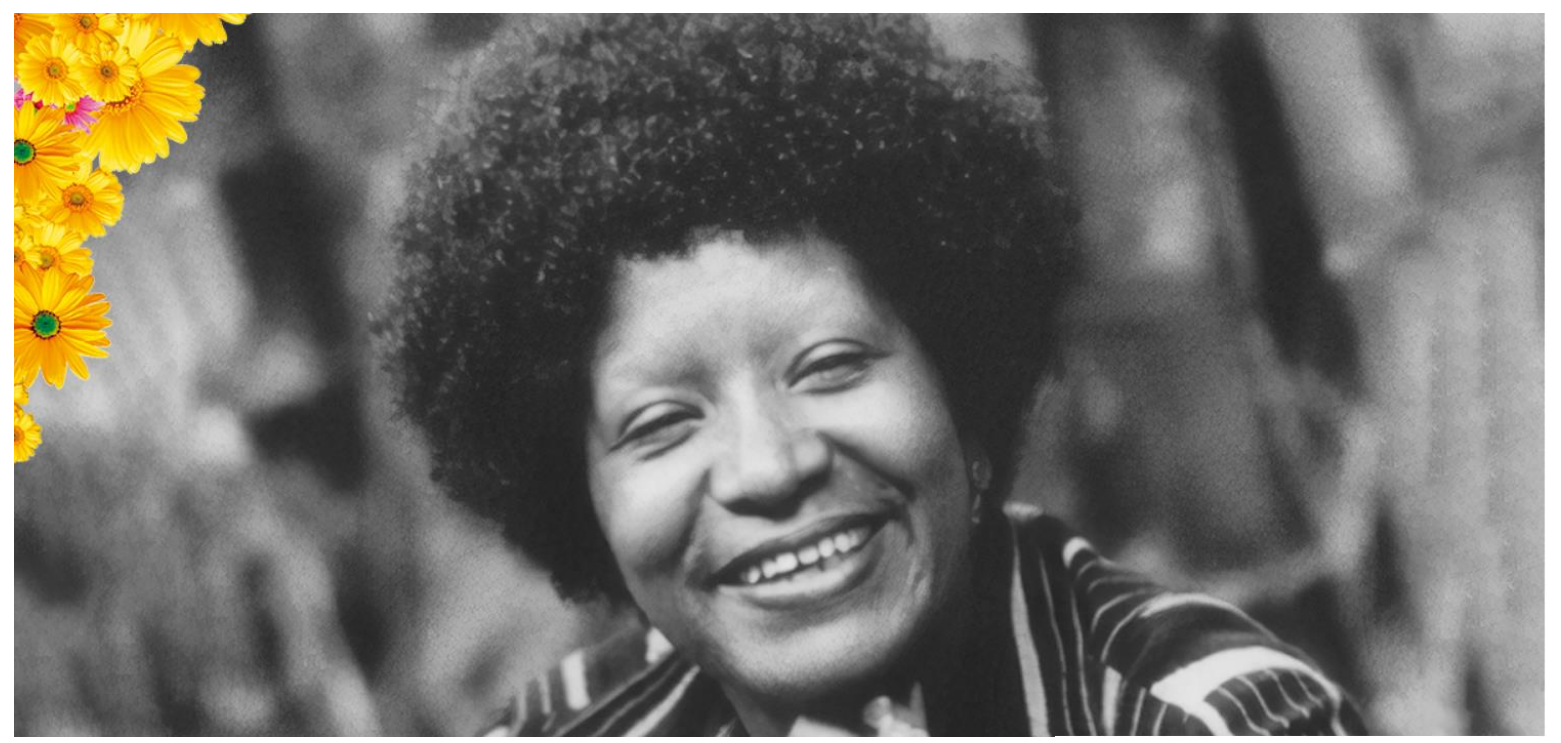

Figura 5. 
Foto de Lélia Gonzalez ${ }^{15}$

Lélia Gonzalez, nascida em Belo Horizonte, Minas Gerais, em 1 de fevereiro de 1935. Gonzalez migra em 1942 para o Rio de Janeiro, lá desenvolvendo a sua vida intelectual. Empenhada pelo seu ativismo e militância nos Movimentos Negros, seguiu uma pauta de total atenção às desigualdades raciais e de gênero no país. Lélia Gonzalez graduou-se em História e Filosofia, lecionou na rede pública de ensino e dedicou-se à Antropologia e Cultura Popular Brasileira na Pontifícia Universidade Católica do Rio de Janeiro (PUC-RJ), onde chefiou o Departamento de Sociologia e Política. Lélia foi uma das precursoras em relação à introdução do estudo sobre o negro nas universidades, questionando principalmente a representação das mulheres negras e indígenas na sociedade brasileira. Pode-se afirmar que o trabalho desenvolvido pela intelectual abriu espaço em diferentes frentes para o reconhecimento da importância da discussão sobre o feminismo negro e ou afrolatinoamericano no contexto social brasileiro. No conjunto variado de atuações da intelectual, destacaria a sua participação no jornal Mulherio ${ }^{16}$, fundado na década de 80 por pesquisadoras da Fundação Carlos Chagas, envolvidas no trabalho de pesquisa sobre a condição feminina no Brasil.

Os movimentos negros brasileiros e, especificamente, o Movimento Negro do Rio de Janeiro abrigou o pensamento de diferentes intelectuais negras desde sua fundação em 1978. Assim como Neusa Santos Souza, Lélia Gonzalez, na sua marcante passagem pelo MNU, foi sinônimo de grande expressão intelectual. O projeto intelectual de Lélia Gonzalez começa antes da sua entrada no movimento. O MNU foi um lugar de importante correspondência com as suas ações intelectuais como filósofa, antropóloga, professora, escritora, intelectual militante e feminista.

Gonzalez teve um projeto alinhado com o efusivo questionamento do que ela chamava de "lugar de negro". Era contra o lugar, de certa forma, predestinado ao negro brasileiro no pósabolição que Lélia planejou suas ações intelectuais de enfretamento com a questão levantada. A sua atuação docente e o compromisso com a formação dos seus alunos pode ser considerado um dos primeiros passos dentro de um projeto que viria a representar, mais tarde, a marca de um

\footnotetext{
${ }^{15}$ Foto disponível em https://revistacult.uol.com.br/home/lelia-gonzalez-perfil/

${ }^{16} \mathrm{O}$ jornal Mulherio é resultado da sistematização, por pesquisadoras e jornalistas, de informações a respeito da condição feminina no Brasil. Especificamente as matérias tratavam sobre os problemas que envolviam a condição das mulheres de forma séria e, ao mesmo tempo, bem humorada. Maiores detalhes sobre as edições encontram-se disponíveis em: https://www.fcc.org.br/conteudosespeciais/mulherio/historia.html.
} 
pensamento intelectual significativo para o estudo das relações raciais no Brasil. Projeto este de relevância extrema no tocante às ambiguidades e contradições presentes nas aproximações entre raça, classe e gênero.

Lélia foi uma das primeiras intelectuais negras a questionar a proposição formativa do movimento feminista no Brasil, cujo recorte apenas de gênero, não seria substancioso para identificar a opressão racial e de classe sofrida pelas mulheres negras e pobres. Lélia Gonzalez foi representante do que ela chamava de "minorias silenciadas". Trabalhou incansavelmente pelo reconhecimento da existência das diferenças raciais relativas ao contexto das mulheres negras e indígenas localizadas na periferia das favelas e nas comunidades mais carentes do país.

A profícua trajetória intelectual de Lélia Gonzalez não nos deixa dúvidas sobre o diálogo que a intelectual fez com intelectuais no MNU e com outros intelectuais fora do movimento. Frantz Fanon foi um desses intelectuais. O espírito revolucionário das ideias de Fanon aparece com muita propriedade nas ideias alavancadas por Lélia Gonzalez de crítica a sua frase emblemática "a gente não nasce negro, a gente se torna negro". Nascer negro, na concepção da autora, pode ser compreendido como a continuidade de um projeto colonial de reprodução do indivíduo negro como inferior, subalterno e alienado à sua própria capacidade humana.

Lélia foi absolutamente crítica do sistema de ensino brasileiro. Segundo a intelectual, o sistema não permite que o sujeito negro tenha liberdade para assumir a sua identidade étnico-racial sem maiores consequências para a maneira como existe socialmente. Ao se pronunciar sobre o processo de embranquecimento pelo qual passa o sujeito negro no sistema pedagógico- escolar, na entrevista para o livro Patrulhas Ideológicas, Lélia afirma, tomando a sua própria experiência como exemplo: "e passei por aquele processo que eu chamo de lavagem cerebral dado pelo discurso pedagógico-brasileiro, porque na medida em que eu aprofundava meus conhecimentos, eu rejeitava cada vez mais a minha condição de negra” (SANTIAGO In ANTELO, 1998, p. 15). Curioso pensar que é através da análise na psicanálise, como paciente, que Lélia Gonzalez se descobrirá negra e que alcançará maior consciência racial e de gênero. Sobre isso, Lélia se pronuncia da seguinte forma:

Meu lance na psicanálise foi muito interessante, a psicanálise me chamou atenção para meus próprios mecanismos de racionalização, de esquecimento, de recalcamento etc. Foi inclusive a psicanálise que me ajudou neste processo de descobrimento da minha negritude. 
[...] Comecei fazendo análise com Carlos Byington, que é jungiano [sic]. (RATTS; RIOS In Pasquim, 1986, p.10)

O encontro de Lélia Gonzalez com a psicanálise leva-nos a pensar duas coisas: primeiro na possibilidade de Lélia e Neusa terem se conhecido no Movimento Negro Unificado no Rio de Janeiro, já que as duas autoras, em 1978, já eram conhecidas pelo trabalho intelectual que institucionalmente desenvolviam. Segundo, é possível também que, de alguma forma, a psicanálise ou o contato com os profissionais da área, tenha aproximado as duas trajetórias, ainda que através de discreto trabalho em conjunto, a princípio. Deve-se lembrar ainda que para a época, duas coisas não eram comuns. Nem pacientes negros procurarem a psicanálise para terapia e nem a presença de psicanalistas negras e negros, no campo de estudos e pesquisa da área, que estivessem atentos, na dinâmica da terapia, à inserção da discussão étnico-racial com questionamentos relativos à construção da identidade racial.

Ao ter descoberto a sua negritude na terapia, Lélia Gonzalez categoricamente atesta que ninguém nasce se reconhecendo como sujeito negro. Esse reconhecimento vem, em parte, dos enfretamentos desse sujeito com o meio social, principalmente, quando percebe à rejeição do meio à existência negra. Lélia tentou se moldar à política do embranquecimento social no Brasil. E durante algum tempo da sua vida, chegou a render-se à "dupla consciência", olhando-se com os olhos do colonizador sobre o seu corpo negro. Mas como filósofa, Lélia buscou respostas a dois questionamentos importantes sobre o enfrentamento com as relações raciais. Um mais particular e relativo ao casamento com um homem branco e o suicídio do mesmo, e o outro que exigiu dela uma radical virada em seus propósitos intelectuais.

Descobrir-se negra para Lélia Gonzalez dialoga diretamente com a discussão de Lewis R. Gordon no livro What Fanon Said ${ }^{17}$, quando precisamente Gordon problematiza, a partir das ideias de Fanon, a experiência vivida do corpo negro. O capítulo cinco, em Pele negra, máscaras brancas, iniciado pelas expressões "Preto sujo!” (...), é considerado por Gordon uma das passagens

\footnotetext{
${ }^{17}$ O livro, What Fanon Said, escrito por Lewis R. Gordon, configura-se como uma objetiva e clara explicação de questões ambíguas e ou equívocos de leitura e interpretação sobre o que Fanon propôs para o enfrentamento da existência negra relacionadas à classe, ao gênero, à sexualidade e à violência do colonialismo e do racismo. A sistemática de análise de Gordon esclarece não só quem é Fanon, mas o que Fanon disse e como suas ideias podem ser incorporadas no debate do mundo contemporâneo. O mais surpreendente no livro é que Gordon consegue atualizar as ideias de Fanon, ampliando a partir da discussão filosófica, a proposição de "uma nova geografia da razão", como alternativa criticamente possível no combate a toda e qualquer racionalidade humana alinhada à opressão. O texto declaradamente representa um profundo mergulho no que Fanon disse e continua a dizer ontem e hoje.
} 
mais influentes do trabalho. Sobre o trecho o autor explica a construção paradoxal, entendida entre elementos irônicos, cujo caráter autobiográfico, ressalta o pensamento de Fanon através de uma acertada aproximação com Ralph Ellison no prólogo do livro Invisible Man. Nas palavras de Gordon:

This passage is perhaps the most influential parto $f$ the work. Its impacto $n$ post1950 s tretemnts of oppression is perhaps equaled only by Ralph Ellison`s prologue to Invisible Man, a text with which it is often discussed in the critical literature. Among the many ironic elements of the passage is its autobiographical status. Its repor tis paradoxical. Fanon annouces the experience of a world that denies his inner life; he examines this supposed absence from the point of view of his inner life. The paradox black experience is thus raised: Black experience should not exist since blacks should not have a point of view. Nonetheless, black experience is all that should exist since a black`s subjective life should not be able to transcend itself to the level of the intersubjective or the social. The prejudice is familiar: Blacks live, at best, on the level of the particular, not the universal. Thus, black experience suffers from a failure to bridge the gap between subjective life and the world $^{18}$. It is na experience that is, according to racista logic, not experience. (GORDON, 2015, p. 48)

O trecho analisado por Gordon diz respeito a seguinte passagem completa na tradução de Pele negra, máscaras brancas em português:

"Preto sujo!" Ou simplesmente: "Olhe, um preto!"

Cheguei ao mundo pretendendo descobrir um sentido das coisas, minha alma cheia de desejo de estar na origem do mundo, e eis que me descubro objeto em meio aos outros objetos.

Enclausurado nesta objetividade esmagadora, implorei ao outro. Seu olhar libertador, percorrendo meu corpo subitamente livre de asperezas, me devolveu uma leveza que eu pensava perdida e, extraindo-me do mundo, me entregou ao mundo. Mas, no novo mundo, logo me choquei com a outra vertente, e o outro, através de gestos, atitudes, olhares, fixou-me como se fixa uma solução com um estabilizador. Fiquei furioso, exigi explicações... Não adiantou nada. Explodi. Aqui estão os farelos reunidos por um outro eu. (FANON, 2008, p. 103)

Assim como Gordon recorre à literatura para ressaltar o impacto da passagem do texto de Fanon, acrescento à discussão filosófica e existencial sobre a existência negra e sua negação o texto do "Emparedado", de Cruz e Souza. De maneira rápida, mas precisa, no "Emparedado", Cruz e Souza problematiza a raça sob o ponto de vista existencial: "As civilizações, as raças, os povos degladiam-se e morrem minados pela fatal degenerescência do sangue, despedaçados, aniquilados no pavoroso túnel da Vida, sentindo o horror sufocante das supremas asfixias" (SOUZA, 2008, p. 609-632). E num outro trecho do texto Cruz e Souza afirma: "Não! Não! Não! Não transporás os

\footnotetext{
${ }^{18}$ Grifo meu.
} 
pórticos milenários da vasta edificação do Mundo, porque atrás de ti e adiante de ti não sei quantas gerações foram acumulando, acumulando pedra sobre pedra, pedra sobre pedra, que para aí estás agora o verdadeiro emparedado de uma raça" (SOUZA, 2008, p. 609-632). Ao longo do texto, Cruz e Souza faz alusão ao emparedamento racial e afirma o quanto isso é sufocante para a existência humana.

\section{Considerações Finais}

Retomando Gordon, em sua análise, o autor afirma que a experiência negra colapsa ao tentar construir uma ponte entre a vida subjetiva e o mundo porque, de acordo com a lógica racista, a experiência negra não é uma experiência. Fanon atestou a rejeição da experiência negra como experiência em seus estudos e na forma como definiu a alienação. Mas o problema não está na experiência subjetiva da existência negra. O problema está na lógica utilizada para o reconhecimento dessa experiência como experiência. E é essa não lógica utilizada para uma definição lógica, afirmo, que nos empareda, conforme alerta Cruz e Souza.

Tanto Neusa Santos Souza quanto Lélia Gonzalez viveram, em suas trajetórias de vida e de produção intelectual e acadêmica dentro de um contexto de uma não lógica sobre a importância do que pensaram e do que efetivamente produziram como intelectuais negras. São consideradas mulheres negras avançadas para o seu tempo porque perceberam, a partir das suas próprias subjetividades negras, o quanto o tornar-se negro não é parte de um processo colapsado no fracasso. O tornar-se negro é parte da descoberta de uma experiência subjetiva, que nos afirma e nos reafirma como sujeitos negros, diretamente ligada à filosofia da racionalidade humana.

A relação que essas intelectuais estabeleceram, prioritariamente, com as ideias de Fanon, a partir dos seus escritos e da sua crítica ao colonialismo e ao racismo, não só influenciaram o que sistematicamente produziram como conhecimento em suas áreas de atuação, mas incidiram também na maneira como elas passaram a si ver no mundo. Ambas mergulharam na proposição de uma descoberta pessoal e intelectual contra a alienação do estado psicológico do ser humano. Foram capazes de, em seus projetos intelectuais, subverter a não lógica circundante no "Ideal do Ego" em estado produtivo da experiência negra. Sem dúvida, são duas experiências femininas e negras, no contexto intelectual brasileiro, que desafiaram tornar o sujeito negro um ser de ação, conforme preconizou Fanon. 


\section{Referências Bibliográficas}

CRUZ e SOUZA, João da. Obras Completas. Rio de Janeiro: Nova Aguilar. 1995.

DU BOIS, W.E.B. The Souls of Black Folk. Chicago: A. C. McClurg \& CO., 1903.

DUARTE, Eduardo de Assis (Org.). Literatura e afrodescendência no Brasil: antologia crítica. Belo Horizonte: Editora da UFMG, 2011.

FANON, Frantz). Pele negra, máscaras brancas; tradução de Renato da Silveira. Salvador: EDUFBA, (1952 [2008]).

FANON, Frantz. Os condenados da terra; tradução Enilce Albergaria Rocha, Lucy Magalhães. Juiz de Fora: Ed. UFJF, 2005.

FERNANDES, Florestan. A integração do negro na sociedade de classes: no limiar de uma nova era. v.II. São Paulo: Dominus Editora,1965.

FREIRE, Paulo. Pedagogia da autonomia: saberes necessários à prática educativa. $60^{\mathrm{a}}$ ed- Rio de Janeiro/São Paulo: Paz e Terra, (1996 [2019]).

GONZALEZ, Lélia; HASENBALG, Carlos. Lugar de negro. Rio de Janeiro: Marco Zero, 1982.

GOMES, Nilma Lino (Org.). Um olhar além das fronteiras: educação e relações raciais. Belo Horizonte: Autêntica, 2010.

GORDON, Lewis R. Editor. Existence in Black- an Anthology of Black Existential Philosophy. New York: Routledge, 1997.

GORDON, Lewis R. An introduction to Africana philosophy. New York: Cambridge University Press, 2008.

GORDON, Lewis R. What Fanon Said: A Philosophical Introduction to His Life and Thought. Forddham University Press: New York, 2015.

HERKENHOFF, A. Racismo: por que se matou a psicanalista negra que fazia sucesso no Rio? Correio do Brasil, a. XII, n. 4444, 20/01/2009.

NASCIMENTO, Abdias. O Genocídio do negro brasileiro: processo de um racismo mascarado. Rio de Janeiro: Paz e Terra, 1978.

PENNA, William Pereira. Escrevivências das memórias de Neusa Santos Souza: apagamentos e lembranças negras nas práticas PSIS. Dissertação (Mestrado no Programa de Pós-Graduação do Instituto de Psicologia) - da Universidade Federal Fluminense, Niterói, p. 124, 2019. 
PEREIRA, Amauri Mendes; SILVA, Joselina da (Orgs.). Movimento Negro Brasileiro: escritos sobre os sentidos de democracia e justiça social no Brasil. Belo Horizonte: Nandyala, 2009.

RATTS, Alex; RIOS, Flávia. Lélia Gonzalez. São Paulo: Selo Negro, 2010.

SILVA, Rosemere Ferreira da. Trajetórias de dois Intelectuais Negros: Abdias Nascimento e Milton Santos. Tese (Doutorado no Programa Multidisplinar de Pós-Graduação em Estudos Étnicos e Africanos) - Faculdade de Filosofia e Ciências Humanas da Universidade Federal da Bahia. Salvador, p. 233, 2010.

SILVA, Rosemere Ferreira da. "Entre o literário e o existencial, a "escrevivência" de Conceição Evaristo na criação de um protagonismo feminino negro no romance Ponciá Vicêncio". Revista EntreLetras, n.1v 8. p. 07-23 jul, 2017.

SOUZA, Florentina da Silva. Afro-descendência em Cadernos Negros e Jornal do MNU. Belo Horizonte: Autêntica, 2005.

SOUZA, Neusa Santos. Tornar-se negro: as vicissitudes da identidade do negro brasileiro em ascensão social. Rio de Janeiro: Edições Graal, 1983.

Recebido em 10 julho de 2020. Aceito em 08 de outubro de 2020. 